Eur. J. Clin. Chem. Clin. Biochem.

Vol. 30,1992 , pp. $371-375$

C 1992 Walter de Gruyter \& Co. Berlin $\cdot$ New York

\title{
Temperature-Dependent Matrix Effect in the Direct Enzymatic Measurement of Blood Glucose
}

\author{
By F. da Fonseca-Wollheim ${ }^{1}, K .-G$. Heinze ${ }^{1}$ and E. Liss ${ }^{2}$ \\ 1 Zentrallaboratorium, Behring-Krankenhaus Berlin-Zehlendorf \\ ${ }^{2}$ Institut für Klinische Chemie und Klinische Biochemie, Klinikum Steglitz der Freien Universität Berlin
}

(Received January 31/April 9, 1992)

\begin{abstract}
Summary: The influence of the high-molecular-mass sample matrix in the direct enzymatic measurement of glucose in haemolysate was investigated by a comparison study using ultrafiltered haemolysate for reference. Haemolysate was obtained by $1: 21$ dilution of whole blood with a solution of digitonin and maleinimide. It was shown that at low protein concentration glucose distributes in a $1: 1$ ratio during ultrafiltration. With a hexokinase/glucose-6-phosphate dehydrogenase procedure excellent agreement was found between values measured in haemolysate (y) and ultrafiltrates (x), when incubation was performed at $25^{\circ} \mathrm{C}(\mathrm{a}=0.047$ $\mathrm{mmol} / \mathrm{l} ; \mathrm{b}=0.99 ; \mathrm{r}=0.999, \mathrm{n}=37) ;$ at $37^{\circ} \mathrm{C}$, however, the same procedure resulted in a non-tolerable systematic deviation in the direct analysis of haemolysate $(\mathrm{a}=-0.426 \mathrm{mmol} / \mathrm{l} ; \mathrm{b}=1.00, \mathrm{r}=0.997, \mathrm{n}=37)$. The precision of measurements in haemolysate and ultrafiltrate was similar (CV 1.0-1.2\%). Since stable reference material with an appropriate matrix is not available, it is important to evaluate haemolysate procedures carefully by comparison studies with patient samples. For reduction of experimental error in such studies we recommend the use of ultrafiltered haemolysate, since this can be analysed side by side with haemolysate in the same run.
\end{abstract}

\section{Introduction}

The hexokinase/glucose-6-phosphate dehydrogenase ${ }^{1}$ ) principle is the basis for both reference and routine measurement of glucose concentration in body fluids. In the generally accepted reference measurement procedure, protein-free supernatant is used for the analysis of serum (1). Field methods preferably omit deproteinization for reasons of simplification, but this may be counterbalanced by a loss of accuracy. Especially in the direct analysis of haemolysate for blood

1) Enzymes: Hexokinase, ATP:D-hexose 6-phosphotransferase, EC 2.7.1.1; Glucose-6-phosphate dehydrogenase, $D$-Glucose-6-phosphate: NADP oxidoreductase, EC 1.1.1.49; Phosphogluconate dehydrogenase, 6-Phospho- $D$-gluconate: $\mathrm{NAD}(\mathrm{P})$ 3-oxidoreductase (decarboxylating), EC 1.1.1.44; Glucosephosphate isomerase, $D$-Glucose-6-phosphate ketol-isomerase, EC 5.3.1.9. glucose (2) the performance of the hexokinase method may be compromised by the high-molecular-mass compounds of the sample matrix, e.g., haemoglobin, erythrocyte phosphogluconate dehydrogenase ${ }^{1}$ ) and glucosephosphate isomerase ${ }^{1}$ ) (3). Although it has been shown that good agreement between glucose values obtained from haemolysate and protein-free supernatant is achievable (3-4), this has to be confirmed whenever a relevant analytical variable in the direct glucose measurement is changed, e.g. the type of haemolysing agent, reagent composition, duration and/or temperature of incubation. Here a new experimental approach is described for such comparison studies, in which haemolysate samples and the corresponding protein-free ultrafiltrates are analysed in the same run. A brief presentation of this principle has already appeared as an abstract (6). 


\section{Methods}

Reagents and solutions

The reagent kit for glucose determination ("Glucoquant", catalog No. 263826), haemolysing agent ("Hemolyzing Reagent", catalog No. 262836), calibrator solution ("Precimat Glucose", catalog No. 125555) and control serum ("Precinorm U", catalog No. 171743 and "Precipath U", catalog No. 171778) were purchased from Boehringer Mannheim, Mannheim, Germany. They were used according to the instructions given by the manufacturer.

\section{Blood samples}

Venous blood samples treated with sodium fluoride and EDTA (final concentrations 50 and $3 \mathrm{mmol} / \mathrm{l}$, respectively) were used throughout the study. For the comparison studies 37 blood samples were selected from the workload of the laboratory according to their glucose concentration to cover the range of 3 to $15 \mathrm{mmol} / \mathrm{l}$.

\section{Sample preparation}

Plasma was obtained by centrifuging blood samples at $1500 \mathrm{~g}$ (10 minutes, room temperature).

Glucose-free matrix material was prepared by gel chromatography of each $2 \mathrm{ml}$ of pooled plasma samples on several Sephadex G-25 M minicolumns (Column PD-10; Pharmacia, Uppsala, Sweden) using $0.15 \mathrm{~mol} / 1 \mathrm{NaCl}$ solution as eluent. The fractions obtained after addition of $2 \mathrm{ml}$ eluent were pooled and concentrated by ultrafiltration at $1800 \mathrm{~g}$. The concentrations of total protein and glucose were $\sim 55 \mathrm{~g} / \mathrm{l}$ (biuret method) and $<0.01 \mathrm{mmol} / \mathrm{l}$, respectively. For the recovery and distribution experiments this matrix material was spiked with 167 mmol/1 D-glucose (catalog No. 8337, E. Merck, Darmstadt, Germany) solution to obtain a final concentration of 16.7 $\mathrm{mmol} / \mathrm{l}$.

Before direct analysis or ultrafiltration the spiked matrix material sample was diluted by mixing 1 part with 20 parts of the haemolysing agent containing $50 \mathrm{mg} / \mathrm{l}$ digitonin and $100 \mathrm{mg} / \mathrm{l}$ maleinimide. Individual blood or plasma samples, calibrator solution and control sera were diluted in the same manner.

\section{Ultrafiltration}

For ultrafiltration, $2 \mathrm{ml}$ of the protein-containing solution were placed on the bottom of a Centrisart I (Cat. No. 12349-E, Sartorius $\mathrm{GmbH}$, Göttingen, Germany) centrifuge tube. After inserting the disposable filtrate collector carrying the semipermeable membrane (cellulose triacetate; cutoff $M_{\mathrm{r}}$ about 20000 ) the tube was centrifuged in a swing head rotor for 40 minutes $(350 \mathrm{~g}$, room temperature), resulting in approx. $1 \mathrm{ml}$ colourless ultrafiltrate.

\section{Measurement of glucose concentration}

Glucose concentrations were measured spectrophotometrically using an Abbott VP Series II Bichromatic Analyser (Abbott Laboratories, Irving, TX, USA). Briefly, $10 \mu$ l blank solution $\left(\mathrm{H}_{2} \mathrm{O}\right)$, dilutions of calibrator solution, control sera or unknown samples (plasma or haemolysate and the corresponding ultrafiltrates) were pipetted together with $250 \mu$ l reagent mixture into a partition of the multicuvette. Four seconds later the first absorbance reading at $340 / 380 \mathrm{~nm}\left(\mathrm{~A}_{1}\right)$ was taken and the difference $\Delta \mathrm{A}$ between the actual $\mathrm{A}_{2}$ reading and the first revolution reading was printed at $124 \mathrm{~s}$. The stability of the $\Delta \mathrm{A}$ readings was monitored until minute 14 . The incubation temperature was set to 25 or $37^{\circ} \mathrm{C}$. The $25^{\circ} \mathrm{C}$ procedure is an adaptation of the hexokinase method, which has been used by us for several years for routine measurement, while the $37^{\circ} \mathrm{C}$ procedure corresponds to the working scheme given by the reagent manufacturer (ref. No. 1281-6357-1439) with the exception of slightly lower final dilution of the sample (1:546 instead of $1: 561$ ).

The $\Delta \mathrm{A}$ for the calibrator solution and the unknowns were obtained as the mean of quadruplicate determinations. Glucose concentrations were calculated using spreadsheet software (PlanPerfect Version 5.1, WordPerfect Corporation Orem, Utah, U.S. A.). The between-run $\mathrm{CV}$ of single measurements was 1.5 and $1.7 \%$ at $25^{\circ} \mathrm{C}$ or 1.4 and $2.2 \%$ at $37^{\circ} \mathrm{C}$ with commercial control sera containing glucose concentrations of 6.3 and $13.1 \mathrm{mmol} / 1$, respectively. The mean values determined by us deviated by -3.0 and $-2.0 \%$ from the assigned reference method values.

\section{Results}

\section{Distribution of glucose during ultrafiltration}

The distribution of glucose during ultrafiltration was checked in preliminary investigations. In seven experiments the average recovery of glucose added to glucose-free matrix material (see "Methods") was 100.3 (range: 97.7-102.5) \%. After 1:21 dilution and ultrafiltration of this material at $350 \mathrm{~g}$ the mean ratio of glucose concentrations: $c_{\text {diluted sample }} / c_{\text {ultrafiltered sample }}$ was 1.004 (range: $0.998-1.017$ ). The glucose concentration in the ultrafiltrate is therefore in close agreement with that of the diluted sample subjected to ultrafiltration.

\section{Stability of indicated absorbance change}

Figure 1 shows the average glucose concentrations $(n=37)$ measured at various time points after the

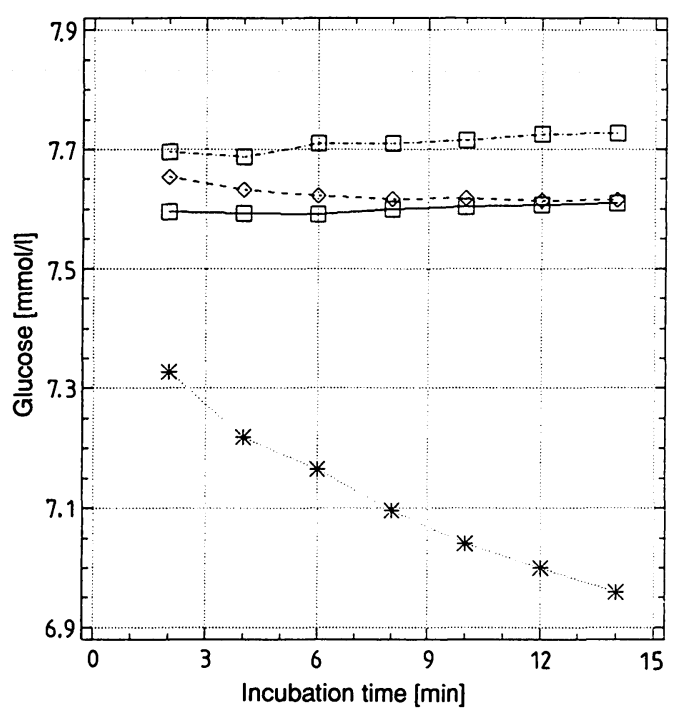

Fig. 1. Influence of incubation temperature and time on the averages of measured glucose concentrations $(\mathrm{n}=37)$ haemolysate at $25^{\circ} \mathrm{C}(\square-\square)$ and $37^{\circ} \mathrm{C}(* \cdots \cdots *)$; ultrafiltrate at $25^{\circ} \mathrm{C}(\diamond--\diamond)$ and $37^{\circ} \mathrm{C}(\square \cdot-\cdot-\square)$. 
Tab. 1. Regression analysis according to Passing \& Bablok (7): Glucose concentrations measured without deproteinization in haemolysate or diluted plasma $(\mathrm{y})$ versus results obtained from corresponding ultrafiltrates $(\mathrm{x}) .4$ min incubation time; $\mathrm{n}=37$

\begin{tabular}{lccccc}
\hline \multirow{2}{*}{$\begin{array}{l}\text { Incubation temperature } \\
\left({ }^{\circ} \mathrm{C}\right)\end{array}$} & \multicolumn{2}{l}{ Haemolysate versus ultrafiltrate } & & \multicolumn{2}{l}{ Diluted plasma versus ultrafiltrate } \\
\cline { 2 - 3 } \cline { 5 - 6 } & 25 & 37 & & 25 & 37 \\
\hline $\begin{array}{l}\text { Intercept } \\
\text { (confidence interval) } \\
\text { (mmol/l) }\end{array}$ & 0.047 & $-0.426^{*}$ & & $(0.050$ & -0.313 \\
Slope & $(-0.048-0.132)$ & $(-0.506-0.321)$ & & $(-0.031-0.126)$ & $(-0.632-0.011)$ \\
(confidence interval) & 0.990 & & & 1.000 & 1.021 \\
$\mathrm{r}$ & $(0.973-1.005)$ & $(0.98-1.009)$ & & $(0.989-1.015)$ & $(0.981-1.070)$ \\
\hline
\end{tabular}

start of the reaction using either ultrafiltered or original haemolysate. It can be seen that the relation between the signals $\left(\Delta \mathrm{A}_{340 / 380 \mathrm{~nm}}\right)$ of ultrafiltered samples and calibrator solution is rather constant for both $25^{\circ} \mathrm{C}$ and $37^{\circ} \mathrm{C}$ incubation. In the presence of original haemolysate the mean value remains virtually constant at $25^{\circ} \mathrm{C}$, while at $37^{\circ} \mathrm{C}$ there is a striking decay of $\Delta \mathrm{A}$ with time.

Influence of the sample matrix on the precision of measurement

The within-run CV calculated from each of 26 measurements of a haemolysate containing $3.7 \mathrm{mmol} / \mathrm{l}$ glucose were 1.1 and $1.0 \%$ for incubation temperatures of $25^{\circ} \mathrm{C}$ and $37^{\circ} \mathrm{C}$, respectively, while the CV with the corresponding ultrafiltrate was $1.2 \%\left(25^{\circ} \mathrm{C}\right)$.

Comparison of glucose concentrations obtained in the analysis of haemolysate or ultrafiltrate

With 37 samples covering the concentration range between 3 and $16 \mathrm{mmol} / \mathrm{l}$ the glucose concentration was determined in haemolysate and ultrafiltered hae-

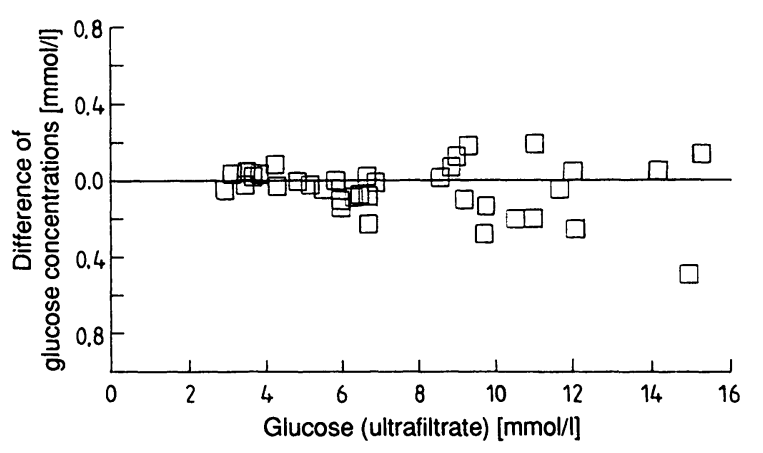

Fig. 2. Comparison of glucose concentrations measured in haemolysate and ultrafiltrate at $25^{\circ} \mathrm{C}$.

The difference $c_{\text {haemolysate }}-c_{\text {ultrafiltrate }}$ is plotted against $c_{\text {ultrafiltrate. }}$

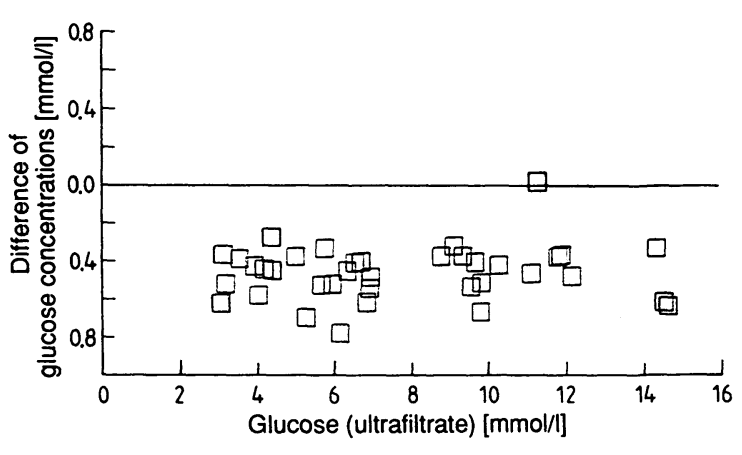

Fig. 3. Comparison of glucose concentrations measured in haemolysate and ultrafiltrate at $37^{\circ} \mathrm{C}$.

The difference $c_{\text {haemolysate }}-c_{\text {ultrafitrate }}$ is plotted against $c_{\text {ultrafiltrate. }}$

molysate, using both the $25^{\circ} \mathrm{C}$ and the $37^{\circ} \mathrm{C}$ procedure (see "Methods"). Analogously diluted plasma was analysed directly or after deproteinization by ultrafiltration. The results of the regression analysis of the paired data according to 1.c. (7) are shown in table 1 . The individual differences between measured glucose concentrations in haemolysate and ultrafiltrate are plotted in figure 2 and 3 for $25^{\circ} \mathrm{C}$ and $37^{\circ} \mathrm{C}$, respectively.

\section{Discussion}

Ultrafiltration for deproteinization of samples

The $1: 21$ dilution of blood or plasma with a corresponding decrease of the protein concentration resulted in a much higher filtration rate, compared with the ultrafiltration of undiluted serum or plasma, as used for the measurement of creatinine (8) or ammonia (9). After $1: 21$ dilution of the blood or plasma proteins their volume displacement effect is negligible, and an $1: 1$ distribution of glucose during ultrafiltration can be anticipated. This was verified by experiments using matrix material with a known concentra- 
tion of added glucose (see "Results"). Interestingly a slight underrepresentation of glucose in the ultrafiltrate in the order of $2-3 \%$ was observed in distribution experiments, if the filtration rate was further increased by centrifuging the ultrafilter at 1700 instead of $350 \mathrm{~g}$ (data not shown).

The advantage of ultrafiltration with respect to conventional deproteinization with protein precipitating agents is that a dilution and contamination of the sample is avoided (6). This assures compatibility of the sample with the analytical system used; differences between results from direct analysis and from ultrafiltrate analysis, which exceed the random variation, can be attributed to non-specificity or interference caused by the high-molecular-mass components.

\section{Use of ultrafiltrates for comparison studies}

Two variants of an automated procedure for direct measurement of glucose concentration in haemolysate or plasma, differing only with respect to the temperature chosen for incubation $\left(25\right.$ or $\left.37^{\circ} \mathrm{C}\right)$, were investigated. The comparison experiments using ultrafiltrates for reference show that at $25^{\circ} \mathrm{C}$ there is good agreement between results, while at $37^{\circ} \mathrm{C}$ measured values deviate systematically by $-0.43 \mathrm{mmol} / 1$ (see tab. 1 and fig. 2 and 3). The cause of this negative deviation of results observed at $37^{\circ} \mathrm{C}$ in the presence of haemolysate has not been identified; its extent is time dependent (see fig. 1). With an alternative hexokinase reagent of different composition inconstant absorbance in direct haemolysate analysis was not observed (10).

The allowable systematic deviation in the measurement of blood glucose derived from accepted guidelines for statistical quality control $(11,12)$ is $5 \%$, e. g.,
$0.25 \mathrm{mmol} / 1$ if the expected value is $5 \mathrm{mmol} / \mathrm{l}$. The use of $37{ }^{\circ} \mathrm{C}$ for glucose determination in haemolysates with the investigated analytical system would therefore require correction of the results by a constant value. Better still, this incubation temperature should be avoided, because the measurement of glucose should be free of bias (13).

As can be seen from the data in table 1, the agreement of results obtained with diluted plasma and the corresponding ultrafiltrates is also better at 25 than at $37^{\circ} \mathrm{C}$. However, the offset and slope obtained in regression analysis did not differ significantly in the $37^{\circ} \mathrm{C}$ procedure from 0 or 1 , respectively.

The present study shows that direct analysis of haemolysate using an incubation temperature of $25^{\circ} \mathrm{C}$ gives a good analytical performance, which is equivalent to a more laborious variant of the method involving deproteinization. This confirms earlier reports on the use of manual (5) or mechanised techniques (14) at room temperature. On the other hand it should be emphasized that variants of the haemolysate procedure (e.g., with incubation at $37^{\circ} \mathrm{C}$ ) should be carefully evaluated before they are implemented for clinical service.

Since a suitable stable reference material for quality control is lacking, comparison studies are essential. The use of ultrafiltered samples for reference as described in this paper appears to be a valuable tool in such studies.

\section{Acknowledgement}

The excellent technical assistance of Mrs. C. Nilgen and Mrs $M$. van Dam is gratefully acknowledged. The work was supported by a grant for a VP Bichromatic Analyser from Abbott Laboratories.

\section{References}

1. Neese, J. W., Duncan, P., Bayse, D., Robinson, M., Cooper, T. \& Stewart, C. (1976) Development and evaluation of a hexokinase/glucose-6-phosphate dehydrogenase procedure for use as a national glucose reference method. HEW Publication No. (CDC)77-8330.

2. Stork, H. \& Schmidt, F. H. (1968) Report on a rapid enzyme technic for the determination of blood sugar in microliters of capillary blood without protein separation and without centrifugation. Klin. Wochenschr. 46, 789790.

3. Haeckel, R. (1970) The rapid, enzymatic determination of glucose in hemolysates. Z. Klin. Chem. Klin. Biochem. 8, $480-482$.

4. da Fonseca-Wollheim, F. (1971) The enzymatic determination of glucose in haemolysed blood samples without interference by fructose. Z. Klin. Chem. Klin. Biochem. 9, $497-502$.
5. Schlebusch, H., Sorger, M., Munz, E., Kessler, A.-Ch. \& Zwez, W. (1980) Determination of glucose in hemolysed blood samples. J. Clin. Chem. Clin. Biochem. 18, 885891.

6. da Fonseca-Wollheim, F. (1989) Ultrafiltrate analysis for the detection of analytical error caused in routine methods by the high molecular sample matrix. J. Clin. Chem. Clin. Biochem. 27, 735 (abstr.)

7. Passing, H. \& Bablok, W. (1983) A new biometrical procedure for testing the equality of measurements from two different analytical methods. J. Clin. Chem. Clin. Biochem. $21,709-720$.

8. da Fonseca-Wollheim, F., Heinze, K.-G., Lomsky, K. \& Schreiner, H. (1988) Serum ultrafiltration for the elimination of endogenous interfering substances in creatinine determination. J. Clin. Chem. Clin. Biochem. 26, 523-525. 
9. da Fonseca-Wollheim, F. (1992) Ultrafiltrate analysis confirms the specificity of the selected method for plasma ammonia determination. Eur. J. Clin. Chem. Clin. Biochem. 30, 15-19.

10. da Fonseca-Wollheim, F. \& Heinze, K.-G. to be published.

11. Stamm, D. (1987) Quality control in clinical laboratories. In: Clinical Chemistry: An Overview (den Boer, N. C., van der Heiden, C., Lejnse, B. \& Sourverijn, J. H. M., eds) New York, Plenum Press, p. 629-640.
12. Stamm, D. (1988) Qualitätsicherung von quantiativen Bestimmungen im Laboratorium. Dt. Ärztebl. 85, 697-712.

13. Fraser, C. G. (1986) Analytical goals for glucose analyses. Ann. Clin. Biochem. 23, 379-389.

14. da Fonseca-Wollheim, F. (1973) A fluorometric hexokinase method for routine determination of glucose with the autoanalyzer. Z. Klin. Chem. Klin. Biochem. 11, 24-30.

Dr. med. F. da Fonseca-Wollheim Zentrallaboratorium

Behring-Krankenhaus Berlin-Zehlendorf

Gimpelsteig 3-5

W-1000 Berlin 37

Bundesrepublik Deutschland 
